\title{
Social Network Sites and Innovation Capabilities in the UAE Hotel Industry. Reliability and Normality Test
}

\author{
Abdulhadi Al-Hammadi, Samer Ali Al-shami, safiahsidek, Abdulla Al-hammadi
}

\begin{abstract}
The integration of information technology through social network sites in business operating and management has been recognized as one of the most resource for the development of innovation capabilities. It plays a significant role in knowledge sharing and transform which are the seeds of innovation development. The service sector is now the main domain where IT plays is extensively integrated in operation and management functions. However, the literature still lacks of clear understanding about the concept of SNSs and the innovation capabilities in hotel industry which affect the effectively use IT in their businesses. Therefore, this study aims to model SNSs and innovation capabilities. The reliability test through Cronbach alpha as well as normality tests were used.
\end{abstract}

Keyword-SNSs, Innovation, UAE, Hotel, Reliability, Normality

\section{INTRODUCTION}

Nowadays, the explosion of pervasive use of internet, social networking sites (SNSs) microblogging has altered the technique in which entrepreneurs improve their companies' performance and innovation. The increased use of Facebook, YouTube, Blog, Twitter, and others lengthways have facilitated the development of entrepreneurship through enabling the entrepreneurs to access into a verity of knowledge which is the key driver of the success (Scuotto, Del Giudice, Peruta, \& Tarba, 2017). Entrepreneurs uncover new methods of conjoining internal and external knowledge taking advantage from market opportunities (Foss, Lyngsie, \& Zahra, 2013; McKelvie, Wiklund, \& Brattström, 2018). On the other hand, companies became more aware about the quality of knowledge and their role on the market opportunity identification and exploitation. Such companies are more attentive on making an equilibrium between innovation and knowledge, in which both factors contribute to their companies' performance and competitive advantage (Nlizwa Rashid, Jabar, Yahya, \& Samer, 2015). However, companies struggle to effectively exploit the opportunities to make up innovations through utilizing expensive knowledge (Scuotto, Giudice, \& Carayannis, 2017). This phenomenon shows the importance of the intensive knowledge in the framework of the entrepreneurship, which guides the

Revised Manuscript Received on April 12, 2019.

Abdulhadi Al-Hammadi, UniversitiTeknikal Malaysia MelakaInstitute of Technology Management and Entrepreneurship. (Email: abdulhadiphd@gmail.com)

Samer Ali Al-Shami, UniversitiTeknikal Malaysia MelakaInstitute of Technology Management and Entrepreneurship.

SafiahSidek, UniversitiTeknikal Malaysia MelakaInstitute of Technology Management and Entrepreneurship.

Abdulla Al-hammadi, UniversitiTeknikal Malaysia MelakaInstitute of Technology Management and Entrepreneurship. tendency of entrepreneurs to handle uncertaintiesand create changes or derive benefits from innovative destructions (Schumpeter, 1934). Nevertheless, as nowadays entrepreneurs compete to generate advanced ideas, there is a rising consciousness that this cannot be achieved without the use of digital techniques (Papa, Santoro, Tirabeni, \& Monge, 2018; Pérez-González, Trigueros-Preciado, \& Popa, 2017). That is due to the fact that companies need to strengthen their capability to take control of outside knowledge predominantly from the cybernetic environment and integrate it with the interior knowledge (Caloghirou, Kastelli, \& Tsakanikas, 2004). Management academics documented such aptitude as absorptive capacity, which is probable to enhance companies in obtaining knowledge from the outside environment (Escribano, Fosfuri, \& Tribó, 2009; Zahra \& George, 2002).

Thus, companies intend to develop inventive thoughts without spending in the internal research tend to produce original knowledge over a collaborative and dynamic method (Leyden \& Link, 2015). The integration of opportunity identification and exploitation helps entrepreneurs to create innovation within new undertakings (Scuotto, Giudice, et al., 2017). Therefore, companies must have the capability to obtain information, integrate it within the knowledge of the company and exploit the newly advanced knowledge (García-Villaverde, Rodrigo-Alarcón, Ruiz-Ortega, \& Parra-Requena, 2018). Generally, examining the existing effect of social networking sites (SNSs) within companies, practitioners and academics indicate that the expansion of SNSs approach hastens and extends companies' service innovation and development by endorsing specialization within, suppliers, clients and other industries (Bharati, Zhang, \& Chaudhury, 2014; Scuotto, Del Giudice, Peruta, et al., 2017). As reported by (Scuotto, Giudice, et al., 2017), 86\% of entrepreneurs state that SNSs are imperative for their companies, 69\% determine to understand knowledge on the platforms, and $66 \%$ want to upsurge blogging accomplishments. (Scuotto, Giudice, et al., 2017) also emphasize the three benefits resulting from the use of SNSs which are i) gaining additional contact (89 $\%)$; ii) contributing to the growth in online movement (75 $\%)$, and iii) leading to higher return (64\%). This, in turn, findings in earlier time to market, earlier product acceptance, and efficiency cost for product development. Yet, despite SNSs have been already introduced by many 
companies in their structural environment to advance their innovation outcome, there has been a lack of familiarity to use the newly digital tools for SNS small and medium firms Scuotto, Giudice, et al., 2017). Therefore, this rsarch aims to Model SNSs and innovation capabilities from the perspective of Hotel industry in the UAE.

\section{SMALL MEDIUM ENTERPRISES IN UAE}

The Small and Medium-sized Enterprises (SMEs) are recognised as business entities which have some culpableness, resources or turnover that is under a certain bound. Definitions of SMEs tend to vary. It is mutable from individual to individual. Many authorized people use the word of SME for the business entities which have less than 500 employees, while others use the term of SME for business entities which have more than 500 employees (Miranda, Lourdes, \& Miranda, 2018). However, there are also others who use the term for the companies which have more than 500 employees.In the United Arab Emirates, SMEs were estimated to have contributed 60 per cent of GDP in 2015 and the Government aims to increase the share to 70 per cent by 2021 (Ahmad, Ahmad, \& Abu Bakar, 2018). The UAE government recognizes the importance of SMEs as the key to economic growth through their significant contribution to GDP and employment opportunities for the majority of private sector employees. Given that SMEs have led productivity growth over the past decade, strengthening the power of SMEs is now essential for the UAE to maintain and improve its competitiveness among dynamic global economies (Ahmad, Abu Bakar, \& Ahmad, 2018). However, there is a lack of a study and framework to help SMEs identify areas where changes are needed to work at a higher level of efficiency. This is critical, since SMEs typically have very limited resources. Faced with enormous uncertainty in today's dynamic and global economy, the decision of SMEs to transform their business operations is challenging and risky (Ahmad, Ahmad, et al., 2018). The resource based view has been recognized as a key driver for the development of SMEs and the literature suggests that the financial and nonfinancial resources are important components for the achievement of competitive advantage. Recently, knowledge base has credited as a key driver for the success of the firms. However, in the context of UAE it received little attention, especially in the promoting SMEs products and sustainability (Ahmad, Abu Bakar, et al., 2018)

The United Arab Emirates is the most lucrative enterprise market in the Arabian Gulf place and the most modern economy amongst the Arab nations. The UAE is already among the 37 countries identified by the Global Competitiveness Report of the World Economic Forum (Schwab, 2013) as an innovation-driven economy. This capacity that innovation contributes to extra than 30 percentage of economic activity, and expertise has turn out to be the driver of growth. Although it is a hydrocarbon-rich country, the UAE government, in line with its Vision 2021, has diagnosed the need to radically change the financial system into a different knowledge-based one to sustain longterm financial increase and generate job opportunities for the country's young and developing population (Pervan, AlAnsaari, \& Xu, 2015). A knowledge-based economy is

characterized by means of speedy innovation (Pervan et al., 2015), so it can be an innovation-driven economy, wherein trade becomes the only authentic constant, and the tempo of change tends to speed up 12 months by year. Moreover, an innovation-driven economy is now not simply structured on complete expenditure on $\mathrm{R} \& \mathrm{D}$, but relies additionally on the efficient allocation of investments and the correct innovation strategy. Strong science and technological know-how abilities as well as gentle and entrepreneurial abilities are necessary in an innovation-driven financial system for creating and distributing new merchandise and modern processes. Innovation, however, comes now not solely from giant corporations, but also from dynamic small and medium organisations (SMEs) which can make fantastic and original contributions to the innovation domain. SMEs have turn out to be primary actors in world markets, pursuing their different innovation strategies and figuring out an excessive share of new products. In the UAE, SMEs account for ninety-two per cent of the complete variety of organizations and make contributions around 50 percent of the GDP generated in the economy; in addition, as many as 200,000 UAE-based SMEs are presently offering over eighty-five percentage of private-sector jobs, according to the UAE Ministry of Economy (2013, p.66).

\section{SOCIAL NETWORKS SITES AND INNOVATION}

According to the RBV, the firms' capabilities and competences that are rare, valuable, unique and distinctive and that have an inadequate movement (Grant, 1991; Peteraf, 1993) are the merely drivers of competitive advantage and advanced returns. Nowadays, SNSs became an important source of any firms which have widely recognized to be an effective business model that influences company's innovation through delivering new knowledge, in inter-organizational learning, that helps to gain a better performance and consolidate companies' competitive advantage (Cohen \& Levinthal, 1990), especially when the firms have capacity to obtain knowledge, integrate it in the company knowledge and exploit the newly developed knowledge (García-Villaverde et al., 2018). Company's generally use SNSs to create, transform, share, and deliberate internet content with international clients (Correia, Medina, Romo, \& Contreras-Espinosa, 2014). Thus, a good costumers' involvement derives from the use of SNSs. (Scuotto, Del Giudice, Peruta, et al., 2017) states that "customers gradually use SMSs not just to seek for services and product but to involve with the firms they purchase from, and customers who may have appreciated ideas". In respect, customers play an active role in promoting innovations (Scuotto, Del Giudice, \& Obi Omeihe, 2017; Scuotto, Giudice, et al., 2017). SNSs enables users to have a voice in proposing a new creative knowledge and decrease the expenditures of innovation research. The innovative ideas that suggested by the customers or others can be transformed into knowledge based on technology by integrating the current knowledge of companies instead of developing and experimenting new things. The diverse way 
of innovation has led to many discussions, leading to the division of scientists on two tracks: first, that exploration is the source of innovation and development, meanwhile the second one advocate that the recreation and utilization of an existing knowledge are the source of innovations (Papa et al., 2018; Pérez-González et al., 2017; Scuotto, Giudice, et al., 2017). Basically, in line with the second stream, we suggest that the collaborative approach is the source of innovation. The online environment is a location of an extensive variety of events such as innovative adaptation or technical catapulting. This is where companies come together with their customers to promote an current product that that includes the change in the original design (Scuotto, Giudice, et al., 2017). The online medium enhances the ability of companies to innovate by streamlining coordinated procedures and facilitating flow on internal and external knowledge. Internet technology facilitates the creation of a supportive environment that facilitates the development of new innovation by simplifying the procedures of gaining external knowledge (Scuotto, Giudice, et al., 2017) In this respect, SNSs are perceived as imperative platforms that have the capacity to influence customers and facilitating innovation development (Papa et al., 2018; Pérez-González et al., 2017; Scuotto, Giudice, et al., 2017).

\section{METHODOLOGY}

A survey was randomly distributed to 5 start hotels in the UAE and the manager of the hotels were the targeted respondents. The survey was distributed to 171 , but the received number was 151 of them 2 uncompleted, meanwhile the final received and completed were 149.

\section{RESULTS}

This study aims to model social network sites and innovation capabilities in hotel industry. The study targets 5star hotels in the UAE. The sample size of the registered sector included 149 hotels. Thus, the entire population was used as a sample of the present research. A survey was used to collect data, meanwhile the targeted respondents were the managers of the hotels. A 7-point Likert scale ranging from 1 ("I strongly disagree") to 7 ("I strongly agree") was utilized to evaluate the respondents. The maximization algorithm (EM) was employed in SPSS to enforce absent significance present statistics. During a course based on Monte Carlo analysis, Arnott and Pervan (2008) stated that an effective EM approach regarding the given statistics has higher reliability and is more detailed in its forecast of the assessment of parameters than techniques such as cutting wisdom that is highly variable and replacing reliable values with undervalued values.

\section{CONSTRUCTS VALIDITY}

First, the composite load factor was used for reliability, and the difference was obtained to assess convergent competencies (Fornellet al., 1981). In this study, the factor loading for all measurements scored over the suggested level of 0.60 (Chin et al., 2017). As shown in Table 1, compound reliability indicating the degree to which construction indicators indicate that the underlying structure ranges between 0.861 and 0.967 is higher than the suggested level 0.7. The mean-variance (AVE), which indicates the total amount of variation in the parameters calculated by passive construction, was in the range from 0.614 to 0.881 , above the suggested level of 0.5 , as endorsed by Rashid \& Shami, (2018) and Hair et al. (2010).

The validity of effective discriminant, which is an amplitude of the rate of whichever conceptual measures differ, has been scrutinized too. The validity of discrimination can be scrutinized by matching effective correlation among the square root and the constructs of the derived inequality (Fornell and Larcker, 1981). The outcome of the analysis determined that the associations per construct were fewer compared to the AVE square root through the meters that measure this construct, showing that this measure has enough discriminating power, as shown in Table 2. This indicates an effective analysis model, which confirmed enough reliability, close competencies, and the power to discriminate. There were several indicators that establish effective suitability of the analysis model. It had a standard 3.65 square meter, which is less than 5. The Comparative Fit Index (CFI) (0.956), Goodness-of-Fit Index (GFI) (0.910), and Non-Normed Fit Index (NNFI) (0.943) all indicated significance of more than the 0.9 cut-off value. Furthermore, the Adjusted Goodness-of-Fit Index (AGFI) obtained 0.873, which surpassed the suggested cut-off level of 0.8 (Schutz, 1970). The square root of the RMSEA (0.08) isequal to the optional level of 0.08 . Therefore, hinging on the effective analysis above, an effective measurement model fitted effective data.

Table 2: Convergent validity

\begin{tabular}{|c|c|c|c|c|}
\hline Constructs & Item loading & \multirow{2}{*}{$\begin{array}{l}\text { Cronbach's } \\
\text { alpha }\end{array}$} & \multirow{2}{*}{ AVE } & \multirow{2}{*}{$\mathbf{C R}$} \\
\hline \multicolumn{2}{|l|}{ Online Social Networks } & & & \\
\hline $\begin{array}{l}\text { W1: blogs are used to issue firm release or to spread } \\
\text { ideas; }\end{array}$ & 0.847 & \multirow{4}{*}{0.91} & \multirow{4}{*}{0.821} & \multirow{4}{*}{0.94} \\
\hline $\begin{array}{l}\text { W2: Hotels employs collaborative software to } \\
\text { communicate with the rest of employees; }\end{array}$ & 0.961 & & & \\
\hline $\begin{array}{l}\text { W3: Hotels employs an intranet for knowledge } \\
\text { management; }\end{array}$ & 0.821 & & & \\
\hline $\begin{array}{l}\text { W4: the site of the hotel allows users to introduce } \\
\text { contents and express their necessities; }\end{array}$ & 0.869 & & & \\
\hline
\end{tabular}




\begin{tabular}{|c|c|c|c|c|}
\hline $\begin{array}{l}\text { W5: employees know suggestions that customers } \\
\text { formulate; }\end{array}$ & 0.839 & & & \\
\hline $\begin{array}{l}\text { W6: the site of the hotelhas, apart from text, } \\
\text { multimedia files to enable the interaction with the } \\
\text { user; }\end{array}$ & 0.644 & & & \\
\hline $\begin{array}{l}\text { W7: hotel develops practices so that employees share } \\
\text { knowledge; and }\end{array}$ & 0.844 & & & \\
\hline $\begin{array}{l}\text { W8: employees keep the know-how of the processes } \\
\text { in an electronic way }\end{array}$ & 0.874 & & & \\
\hline \multicolumn{2}{|l|}{ Innovation } & \multirow{7}{*}{0.95} & \multirow{7}{*}{0.891} & \multirow{7}{*}{0.972} \\
\hline I1: our hotel frequently tries out new ideas; & 0.921 & & & \\
\hline I2: our hotel seeks out new ways to do things; & 0.921 & & & \\
\hline I3: our hotel is creative in its methods of operation; & 0.901 & & & \\
\hline $\begin{array}{l}\text { I4: our hotel is often the first to market with new } \\
\text { products and services; }\end{array}$ & 0.939 & & & \\
\hline $\begin{array}{l}\text { I5: innovation in our hotel is perceived as too risky } \\
\text { and is resisted; and }\end{array}$ & 0.914 & & & \\
\hline $\begin{array}{l}\text { I6: our new product introduction has increased over } \\
\text { the last five years }\end{array}$ & 0.911 & & & \\
\hline
\end{tabular}

\section{CONCLUSION}

The literature suggests that SNSs have positive effect on innovation capabilities. However, both of those two concepts were defined differently from one study to another and from one industry to another. This leaves an opened gap in how to define the concept of SNSs as well as innovation capabilities from Hotel perspectives. Thus, this study aims at examining the reliability and normality of those two constructs. As shown in Table 2, SNSs were defined under eight items, meanwhile innovation capabilities are defined under six items. This study provides a new insight on how hotels can develop their innovation capabilities in extending new market, introducing new products, services and improving management and operation through the integration of SNSs.

\section{REFERENCES}

1. Ahmad, S. Z., Abu Bakar, A. R., \& Ahmad, N. (2018). Social media adoption and its impact on firm performance: the case of the UAE. International Journal of Entrepreneurial Behavior \& Research, IJEBR-08-20170299. https://doi.org/10.1108/IJEBR-08-2017-0299

2. Ahmad, S. Z., Ahmad, N., \& Abu Bakar, A. R. (2018). Reflections of entrepreneurs of small and medium-sized enterprises concerning the adoption of social media and its impact on performance outcomes: Evidence from the UAE. Telematics and Informatics, 35(1), 6-17. https://doi.org/10.1016/j.tele.2017.09.006

3. Arnott, D., \& Pervan, G. (2008). Eight key issues for the decision support systems discipline. Decision Support Systems, $\quad 44(3)$, 657-672. https://doi.org/10.1016/j.dss.2007.09.003

4. Bharati, P., Zhang, C., \& Chaudhury, A. (2014). Social media assimilation in firms: Investigating the roles of absorptive capacity and institutional pressures. Information Systems Frontiers, 16(2), 257-272. https://doi.org/10.1007/s10796-013-9433-x

5. Caloghirou, Y., Kastelli, I., \& Tsakanikas, A. (2004). Internal capabilities and external knowledge sources: Complements or substitutes for innovative performance?
Technovation,

24(1),

29-39.

https://doi.org/10.1016/S0166-4972(02)00051-2

6. Chalkiti, K., \& Sigala, M. (2008). Information sharing and knowledge creation in online forums: The case of the Greek online forum "DIALOGOI." Current Issues in Tourism, 11(5), $381-406$ https://doi.org/10.1080/13683500802316006

7. Chin, W. Y., Ch'ng, C. K., Jamil, J. M., \& Shaharanee, I. N. M. (2017). Analyzing the factors that influencing the success of post graduates in achieving graduate on time (GOT) using analytic hierarchy process (AHP) (p. 040009). https://doi.org/10.1063/1.5012197

8. Cohen, W. M., \& Levinthal, D. A. (1990). Absorptive Capacity: A New Perspective on Learning and Innovation. Administrative Science Quarterly, 35(1), 128 https://doi.org/10.2307/2393553

9. Correia, P. A. P., Medina, I. G., Romo, Z. F. G., \& Contreras-Espinosa, R. S. (2014). The importance of Facebook as an online social networking tool for companies. International Journal of Accounting and Information Management. https://doi.org/10.1108/IJAIM08-2013-0050

10. Escribano, A., Fosfuri, A., \& Tribó, J. A. (2009). Managing external knowledge flows: The moderating role of absorptive capacity. Research Policy, 38(1), 96-105. https://doi.org/10.1016/j.respol.2008.10.022

11. Fornell, C., \& Larcker, D. (1981). Evaluating structural equation models with unobservable variables and measurement error. Journal of Marketing Research, 18(3), 39-50. https://doi.org/10.2307/3151312

12. Fornell, C., Larcker, D. F., \& Modeling, S. (1981). Evaluating Structural Equation Models with Unobservable Variables and Measurement Error. Journal of Marketing Research (JMR). Feb1981, 18(1), 39-50. 12p. 1 Diagram. https://doi.org/10.2307/3151312

13. Foss, N. J., Lyngsie, J., \& Zahra, S. A. (2013). THE ROLE OF EXTERNAL KNOWLEDGE SOURCES AND ORGANIZATIONAL DESIGN IN THE PROCESS OF OPPORTUNITY EXPLOITATION. Strategic Management Journal, 34, 1453-1471. https://doi.org/10.1002/smj 
14. García-Villaverde, P. M., Rodrigo-Alarcón, J., RuizOrtega, M. J., \& Parra-Requena, G. (2018). The role of knowledge absorptive capacity on the relationship between cognitive social capital and entrepreneurial orientation. Journal of Knowledge Management, JKM-07-2017-0304. https://doi.org/10.1108/JKM-07-2017-0304

15. Hair, Black, W. C., Babin, B. J., \& Anderson, R. E. (2010). Multivariate data analysis :global perspective.

16. Kaplan, A. M., \& Haenlein, M. (2010). Users of the world, unite! The challenges and opportunities of Social Media. Business Horizons,53(1), 59-68. https://doi.org/10.1016/j.bushor.2009.09.003

17. Leyden, D. P., \& Link, A. N. (2015). Toward a theory of the entrepreneurial process. Small Business Economics, 44(3), 475-484. https://doi.org/10.1007/s11187-014-96060

18. McKelvie, A., Wiklund, J., \& Brattström, A. (2018). Externally Acquired or Internally Generated? Knowledge Development and Perceived Environmental Dynamism in New Venture Innovation. Entrepreneurship Theory and Practice, 42(1),

24-46. https://doi.org/10.1177/1042258717747056

19. Miranda, A. T., Lourdes, J., \& Miranda, F. (2018). Asia Pacific Journal of Innovation and Entrepreneurship Status and conditions of small-and medium-sized enterprises as predictors in empowering rural communities in Samar Island, Philippines Article information. Asia Pacific Journal of Innovation and Entrepreneurship, 12(1), 105119. https://doi.org/10.1108/APJIE-12-2017-0045

20. Papa, A., Santoro, G., Tirabeni, L., \& Monge, F. (2018). Social media as tool for facilitating knowledge creation and innovation in small and medium enterprises. Baltic Journal of Management, 13(3), 329-344. https://doi.org/10.1108/BJM-04-2017-0125

21. Pérez-González, D., Trigueros-Preciado, S., \& Popa, S. (2017). Social Media Technologies' Use for the Competitive Information and Knowledge Sharing, and Its Effects on Industrial SMEs' Innovation. Information Systems Management, 34(3), 291-301. https://doi.org/10.1080/10580530.2017.1330007

22. Pervan, S., Al-Ansaari, Y., \& Xu, J. (2015). Environmental determinants of open innovation in Dubai SMEs. Industrial Marketing Management. https://doi.org/10.1016/j.indmarman.2015.05.029

23. Rashid, N., \& Shami, S. A. (2018). Business Model for Sustainable Development: An Insight from Malaysian Automotive Industry. International Journal of Human and Technology Interaction, 2(1), 77-82.

24. Rashid, Nlizwa, Jabar, J., Yahya, S., \& Samer, S. (2015). State of the Art of Sustainable Development: An Empirical Evidence from Firm's Resource and Capabilities of Malaysian Automotive Industry. Procedia - Social and Behavioral Sciences, 195(2015), 463-472. https://doi.org/10.1016/j.sbspro.2015.06.488

25. Schumpeter, J. . (1934). The theory of economic development. Boston: Harvard University Press.

26. Schutz, A. (1970). On Phenomenology and Social Relations. Chicago: University of Chicago Press.

27. Scuotto, V., Del Giudice, M., \& Obi Omeihe, K. (2017). SMEs and Mass Collaborative Knowledge Management: Toward Understanding the Role of Social Media Networks. Information Systems Management, 34(3), 280290. https://doi.org/10.1080/10580530.2017.1330006

28. Scuotto, V., Del Giudice, M., Peruta, M. R. della, \& Tarba, S. (2017). The performance implications of leveraging internal innovation through social media networks: An empirical verification of the smart fashion industry. Technological Forecasting and Social Change, 120, 184194. https://doi.org/10.1016/j.techfore.2017.03.021

29. Scuotto, V., Giudice, M. Del, \& Carayannis, E. G. (2017). The effect of social networking sites and absorptive capacity on SMES' innovation performance. Journal of Technology Transfer, 42(2), 409-424. https://doi.org/10.1007/s10961-016-9517-0

30. Zahra, S. a., \& George, G. (2002). Absorptive capacity: A review, reconceptualization, and extension. Academy of Management

Review. 